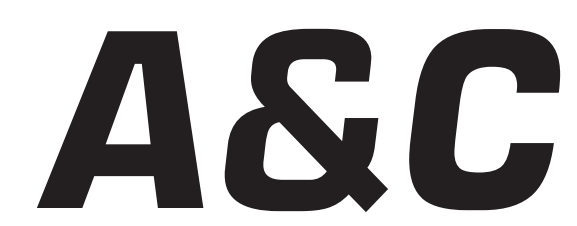

Revista de Direito Administrativo \& Constitucional

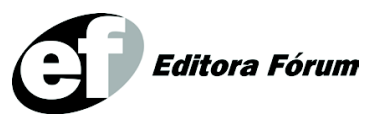

ISSN 1516-3210 


\section{A\&C REVISTA DE DIREITO ADMINISTRATIVO E CONSTITUCIONAL}

IPDA

Instituto Paranaense

de Direito Administrativo

Direção Geral

Romeu Felipe Bacellar Filho

Direção Editorial

Paulo Roberto Ferreira Motta

Direção Executiva

Emerson Gabardo

Conselho de Redação

Edgar Chiuratto Guimarães

Adriana da Costa Ricardo Schier

Célio Heitor Guimarães

\section{Conselho Editorial}

Adilson Abreu Dallari

Alice Gonzáles Borges

Carlos Ari Sundfeld

Carlos Ayres Britto

Carlos Delpiazzo

Cármen Lúcia Antunes Rocha

Celso Antônio Bandeira de Mello

Clèmerson Merlin Clève

Clóvis Beznos

Enrique Silva Cimma

Eros Roberto Grau

Fabrício Motta

Guilhermo Andrés Muñoz (in memoriam)

Jaime Rodríguez-Arana Muñoz

Jorge Luís Salomoni

José Carlos Abraão
José Eduardo Martins Cardoso
José Luís Said
José Mario Serrate Paz
Juan Pablo Cajarville Peruffo
Juarez Freitas
Julio Rodolfo Comadira
Luís Enrique Chase Plate
Lúcia Valle Figueiredo
Manoel de Oliveira Franco Sobrinho
(in memoriam)
Marçal Justen Filho
Marcelo Figueiredo
Márcio Cammarosano
Maria Cristina Cesar de Oliveira

Nelson Figueiredo

Odilon Borges Junior

Pascual Caiella

Paulo Eduardo Garrido Modesto

Paulo Henrique Blasi

Paulo Neves de Carvalho (in memoriam)

Paulo Ricardo Schier

Pedro Paulo de Almeida Dutra

Regina Maria Macedo Nery Ferrari

Rogério Gesta Leal

Rolando Pantoja Bauzá

Sérgio Ferraz

Valmir Pontes Filho

Yara Stropa

Weida Zancaner

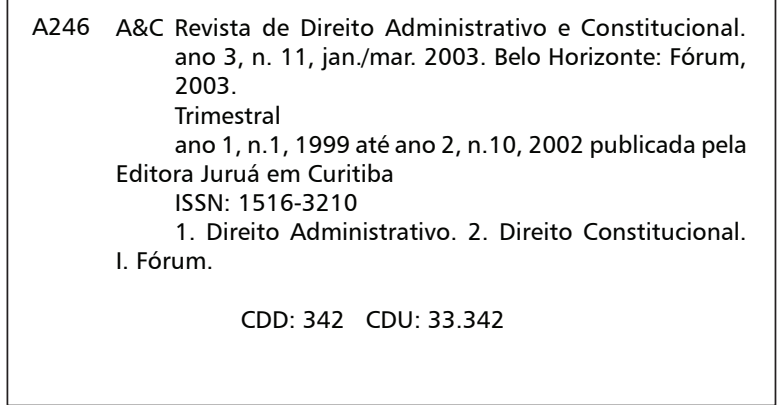

(C) Editora Fórum Ltda. 2007

Todos os direitos reservados. É proibida a reprodução total ou parcial, de qualquer forma ou por qualquer meio eletrônico ou mecânico, inclusive através de processos xerográficos, de fotocópias ou de gravação, sem permissão por escrito do possuidor dos direitos de cópias (Lei nº 9.610, de 19.02.1998).

Editora Fórum Ltda

Av. Afonso Pena, 2770 - 15\%16ª andar - Funcionários

CEP 30130-007 - Belo Horizonte/MG - Brasil

Tel.: 08007043737

Internet: www.editoraforum.com.br

e-mail: editoraforum@editoraforum.com.br
Editor responsável: Luís Cláudio Rodrigues Ferreira Projeto gráfico e diagramação: Luis Alberto Pimenta Revisora: Olga M. A. Sousa

Pesquisa jurídica: Fátima Ribeiro - OAB/MG 74868

Bibliotecária: Alessandra Rodrigues da Silva CRB 2778/MG 6 ${ }^{\text {a Região }}$

Os conceitos e opiniões expressas nos trabalhos assinados são de responsabilidade exclusiva de seus autores.

Impressa no Brasil / Printed in Brazil

Distribuída em todo Território Nacional 


\title{
Limites de esgotamento da lei e do regulamento como fontes do Direito Administrativo no Brasil: aspectos introdutórios*
}

\author{
Rogério Gesta Leal \\ Desembargador do Tribunal de Justiça do Estado do Rio Grande do Sul. Doutor em Direito. Professor \\ Titular da Universidade de Santa Cruz do Sul. Professor Colaborador da Universidade Estácio de Sá. \\ Professor Visitante da Università Túlio Ascarelli - Roma Trè, Universidad de La Coruña - Espanha, \\ e Universidad de Buenos Aires. Membro do Foro Ibero-Americano de Direito Administrativo, do \\ Instituto Brasileiro de Direito Administrativo e do Instituto Riograndense de Direito Administrativo.
}

Resumo: O presente trabalho pretende abordar o tema da lei e do regulamento como fontes formais e tradicionais do Direito Administrativo, bem como as suas insuficiências em face das novas relações sociais.

Palavras-chave: Fontes do Direito. Lei e Regulamento. Hermenêutica.

Sumário: 1 Notas introdutórias - 2 As fontes do Direito: velhos e novos problemas - 3 Insuficiências teóricas e pragmáticas no âmbito das fontes tradicionais do Direito contemporâneo - 4 Possibilidades empírico-criticistas de soluções às insuficiências das fontes tradicionais do Direito Administrativo - Referências

\section{Notas introdutórias}

Pretendo no presente ensaio trazer à discussão o tema da lei e do regulamento como fonte do Direito Administrativo contemporâneo e no Brasil, haja vista os cenários sociais cada vez mais complexos que estão a caracterizar o contexto de atuação da Administração Pública nesta quadra histórica. Para tanto, pretendo analisar as perspectivas tradicionais que delimitam as possibilidades conceituais e pragmáticas das fontes do direito, verificando de que forma elas são decisivas na demarcação das fontes do Direito Administrativo e mesmo na enucleação do seu objeto. Passo seguinte, vou identificar alguns pontos de estrangulamento daqueles modelos categoriais em face dos desafios hodiernos que se apresentam à Administração Pública.

\section{As fontes do Direito: velhos e novos problemas}

\footnotetext{
* Trabalho a ser apresentado no IV Foro Ibero-Americano de Direito Administrativo, realizado na Universidade Externado da Colômbia, nos dias 24 a 27 de julho de 2007.
} 
Mata Machado indica que os estudiosos do direito consideram o problema das fontes do direito como o saber donde dimana a juridicidade das normas que se impõem à conduta do homem na sociedade. ${ }^{1}$

Mesmo administrativistas mais tradicionais no Brasil, como Cretella Jr., concordam com o fato de que há uma certa dificuldade encontrada mesmo pelos autores da teoria geral e de filosofia do direito de conceituar o que é fonte de direito, tendo em vista aqui que elas dizem respeito, direta ou indiretamente, por excelência, ao ser humano, à natureza humana. ${ }^{2}$

As fontes costumam ser divididas em escritas e não escritas. Novamente a divisão do direito pelas suas fontes, de modo genérico, traz a lei como primeira espécie. As leis, no sentido que aqui se deseja impor, ou melhor, leis escritas, são chamadas de Constituição ou Lei Maior, Carta Magna etc.; Emenda Constitucional, Lei Complementar, Lei Ordinária, Medida Provisória, Regulamento, entre outros. ${ }^{3}$ As fontes não escritas, por sua vez, são a jurisprudência, os costumes e os princípios gerais do direito. A doutrina também é considerada, por alguns autores, fonte de direito, enquanto, para outros, em razão do princípio da legalidade, só a lei é fonte do direito administrativo. ${ }^{4}$

Em relação às espécies das fontes do direito administrativo, são as mesmas escritas e não escritas. Fontes escritas são as leis num sentido amplo, estando incluídas no conceito da Constituição da República até o mais simples ato administrativo normativo, enquanto que as fontes não escritas são tidas, tradicionalmente, como a jurisprudência, costumes e princípios gerais do direito, havendo dúvidas a respeito da doutrina como fonte de direito administrativo. ${ }^{5}$

A lei pode ser considerada uma regra geral, abstrata e impessoal. É a fonte mais importante do direito administrativo. As leis de todos os níveis de governo são consideradas fontes de direito administrativo. É de se notar, entretanto, que só a lei que trata de relações de direito administrativo pode ser considerada fonte do mesmo. A vigência da lei também é requisito fundamental para que esta seja considerada fonte deste ramo do direito. ${ }^{6}$

\footnotetext{
MATA MACHADO. Elementos de teoria geral do direito, p 237-238. De igual sorte, ver o texto de NORONHA. Direito e sistemas sociais: a jurisprudência e a criação do direito para além da lei, 1998.

2 CRETELLA JR. Curso de direito administrativo, p. 169-173.

3 Ver o texto de MIRANDA. Fontes e evolução do direito civil brasileiro, p. 32 et seq.

4 Neste sentido ver o texto de GASPARINI. Direito administrativo, p. 25. Observa o autor que a fonte do direito é o lugar no qual se dá a exteriorização do direito. As fontes do direito administrativo logo seriam os modos pelos quais este é formalizado.

5 RIVERO. Direito administrativo, p. 82.
} 
No tocante à jurisprudência, este conjunto de decisões em um mesmo sentido a respeito da aplicação do direito, ela pode ser considerada como fonte não escrita de grande relevância no direito administrativo, e assim o tem sido, como vamos ver mais adiante, sendo que, nos Estados Unidos e Inglaterra, ela é dotada de força coercitiva, até em face do modelo distinto de organização estrutura e funcional do sistema jurídico mais comunitário do que romano-gêrmanico (destacando-se o crescimento gradativo do direito escrito nestes países). ${ }^{7}$

Por sua vez, o costume, que se constitui em forma não escrita de revelação do direito, considerado como repetição uniforme de um comportamento tido como legal, no âmbito do direito administrativo, tem suprido as deficiências da legislação, a despeito das diferentes famílias jurídicas existentes no Ocidente, em face inclusive de reproduzir, com mais fidelidade, as tendências de composição de demandas sociais em face do Poder Público cada vez mais contundentes. ${ }^{8}$

Contando-se ainda com os princípios gerais de direito, enquanto proposições fundamentais hauridos do próprio sistema jurídico e das instituições que ele criou ao longo do tempo, localizados na base de toda a legislação, junto com os princípios constitucionais de direito, tomaram relevo neste final de século XX, o que tratarei mais adiante. ${ }^{9}$

Por uma questão de ordenação e mesmo em face da proposta de abordagem deste ensaio, vou tratar primeiro da lei como fonte do direito administrativo. Por lei podemos entender da Constituição aos atos normativos mais simples, a saber, exemplificativamente: constituições, leis complementares, leis ordinárias, medidas provisórias, regulamentos, instruções etc. De qualquer forma, só são fontes de direito administrativo aquelas que dispõem sobre relações de interesse ao direito administrativo. Costumam ser as leis que regem os órgãos, os agentes e as atividades públicas.

Por certo que, neste particular, a lei é tomada no sentido amplo, genérico e compreende todo o conjunto de normas escritas, desde a

\footnotetext{
6 Ressalte-se, sempre na perspectiva do Direito Administrativo mais clássico e liberal. Neste sentido, com excelente posição crítica, ver o texto de ALFONSO. Derecho administrativo, p. 38.

7 RICO. Princípios generales de organización de las Administraciones Públicas, p. 69 et seq.

8 Ver para tanto o texto de BETANCOR. Las Administraciones independientes: um reto para el Estado social y democratico del derecho, 2002, especialmente a partir da p. 51.

9 Já abordei este tema em meu livro LEAL. Estado, sociedade e Administração Pública, 2006.
} 
Constituição até o mais simples regulamento, no que for pertinente à Administração Pública.

Se de um lado é forçoso reconhecer que a fonte imediata e principal do direito é a lei, afigura-se de difícil aceitação que esta lei contemple toda a existência humana na sociedade, ou seja, não se pode prever nas leis as infinitas formas de ação existentes nos diferentes grupos sociais. Como conseqüência disso, é necessária a existência de fontes subsidiárias de direito, para revelar quando as leis forem omissas, razão pela qual — de igual forma historicamente - tem-se aceitado a utilização da analogia e da interpretação no processo de aplicação da lei, de forma que seus dispositivos contem com a necessária extensão e flexibilidade demandada pelos casos concretos aos quais se projetam.

Além da lei como expressão convergente da vontade geral, existem também os costumes, o regulamento, a prática administrativa, a doutrina, a jurisprudência, a analogia, a eqüidade, os princípios gerais de direito, os tratados internacionais, o estatuto autônomo, a instrução e a circular, dentre outras manifestações, escritas ou não, que surtam efeitos jurídico-administrativos. Todos estes elementos constituem um universo integrado de fontes do direito, os quais, variando o tempo e o espaço em que são considerados, merecem maior ou menor atenção comunitária (ou mais positivista, dando ênfase desmesurada à norma escrita, ou menos codificada, com destaque à experiência e costumes consolidados).

$\mathrm{Na}$ doutrina especializada, enquanto Gordillo ${ }^{10}$ aponta as fontes nacionais do direito administrativo argentino como a Constituição, a lei, os regulamentos e as fontes materiais de direito administrativo, destacando-se no particular a jurisprudência, o costume e a doutrina, Marcelo Caetano $^{11}$ considera a lei e o costume as principais fontes do direito português, destacando que o melhor critério para distinguir as duas fontes é o grau de consciência que os membros da sociedade tenham a respeito da origem da obrigatoriedade da norma.

Como bem lembra Caio Tácito, o Direito Administrativo é ciência jurídica de recente autonomia, fruto do liberalismo político, sendo que, em eras mais remotas, como a do Direito Romano, a matéria administrativa fazia parte do corpus juris civilis e era composta de normas e princípios de vida comunitária, portanto, tema integrante do direito público. ${ }^{12}$

${ }^{10}$ GORDILLO. Tratado de derecho administrativo, p. 13-14.

${ }^{11}$ CAETANO. Direito administrativo, p. 64-67.

A \& C R. de Dir. Administrativo e Constitucional, Belo Horizonte, ano 7, n. 28, p. 11-26, abr./jun. 2007 
Já no feudalismo, predominava o absolutismo e não existia conteúdo jurídico limitativo, em face da vontade do soberano como lei suprema, sendo que a partir do século XVIII, pode-se visualizar a subordinação estatal ao regime de legalidade. É o advento da lei francesa que sistematizou a Administração Pública (28 de pluvioso, do ano VIII, ou 28 de fevereiro de 1800). A partir de então, estava caracterizada a tripartição dos poderes e todas as demais conseqüências surgidas a partir desta nova concepção mundial de organização política. ${ }^{13}$ A partir de então, em França, ao longo do século XIX, houve estudos sistemáticos de direito administrativo, com ressalva à construção jurisprudencial do Conselho de Estado Francês. Na Itália e na Alemanha, verificou-se a progressiva evolução da doutrina administrativa, sob a influência francesa, enquanto que, na Inglaterra, pode-se identificar o repúdio ao direito administrativo pelo mesmo ser considerado incompatível com o sistema inglês de supremacia do Parlamento e do Judiciário. ${ }^{14}$

De qualquer sorte, a questão que ainda gostaria de problematizar, por enquanto, é mesmo a dos limites epistêmicos e hermenêuticos destas fontes tradicionais do direito em face do perfil e da natureza cada vez mais complexa das relações sociais, e destas para com a Administração Pública.

\section{Insuficiências teóricas e pragmáticas no âmbito das fontes tradicionais do Direito contemporâneo}

Implica desde logo ter presente, aqui e em meu sentir, que a construção de qualquer ordem jurídica não provém jamais de uma razão única e simples que a crie (Monarca, Imperador, Estado), mas trata-se mais propriamente de uma sedimentação contínua na qual se combinam experiências e expectativas múltiplas. ${ }^{15}$ De outro lado, não deixo de reconhecer que foram os Estados modernos os que melhor racionalizaram o processo controlado e regrado de constituição dos ordenamentos jurídicos, transformando a lei como fonte primeira do direito. Todavia, o que Estado ou Processo Legislativo não pode conter ou controlar foi o fenômeno da utilização mais ou menos anárquica de formas jurídicas

\footnotetext{
12 TÁCITO, Caio. Direito administrativo. Revista de Direito Administrativo, p. 35.

${ }^{13}$ BONNARD, Roger. Précis de Droit Administratif. Paris: LGDJ, 2001, p. 49.

${ }^{14}$ Conforme o texto de GRECO, Guido. Argomenti di diritto amministrativo, p. 55 et seq.

15 Já tive oportunidade de discutir isto melhor em meu livro LEAL, Rogério Gesta. Hermenêutica e direito:

considerações sobre a teoria do direito e os operadores jurídicos, 2002.
} 
que perdem sua simplicidade, ou até mesmo sua identidade, em face dos mecanismos e experimentações contingenciais de uso da lei pelas comunidades vivas e mutáveis para as quais ela foi criada. ${ }^{16}$

Esta função dos sistemas normativos racionalmente estruturados por suas fontes oficiais no sentido de ordenar com previsibilidade e segurança os comportamentos sociais como um todo, de forma coerente e hierarquizada, tem se visto em crises sucessivas, desde a órbita das experiências da integração européia, até mesmo envolvendo situações que se encontram a margem do Estado-Nação e da lei formal - como é o caso das relações econômicas que se dão no imenso mercado informal que existe em todo o mundo (a começar pela pirataria de produtos, violação de direitos autorais pela rede virtual de comércio, etc.), impondo-se, de forma inexorável, aceitar, no mínimo, a existência de múltiplas formas e fórmulas de atos e fatos sociais que, apesar de não estarem prima facie albergados pelo sistema oficial, têm ampla aceitação e prática comunitária, a ponto de representar universo imenso de situações fáticas consolidadas no tempo, gerando conseqüências jurídicas (como é o caso dos contratos de compra e venda de gaveta, absolutamente irregulares, mas que geram faticamente a transferência da posse do imóvel, envolvendo imóveis financiados pelo sistema financeiro de habitação no Brasil). ${ }^{17}$

Estou falando aqui de um pluralismo de práticas societais que estão a gerar níveis de complexidade regulatória extremamente agudos em face dos parâmetros das fontes tradicionais do direito e de suas incapacidades ordenatórias eficaciais, deixando à margem do Estado vários tipos

\footnotetext{
${ }^{16}$ Quantas vezes uma norma criada para atingir um fim foi totalmente desvirtuada deste em função das diferentes formas de compreensão e interpretação que as relações sociais deram a ela. Neste sentido, sugiro a leitura do texto de CHEVALLIER, Jean Jacques. L'ordre pratique. In: . . Le droit en procés, p. 91 et seq.

${ }_{17}$ Quero sustentar aqui, junto com Morin, a importância dos juristas nos darmos conta, a partir de um pensar complexo (tal qual a natureza da sociedade em que estamos inseridos), de que o direito, depois de um longo período de submissão à teologia, e depois à filosofia, passou a encontrar-se ligado às ciências duras, ao menos nas representações e metáforas utilizadas. Em face disto, as percepções normativistas que informam os institutos jurídicos e suas dimensões pragmáticas foram herdadas de uma concepção mecanicista do sistema político: pesos e contrapesos (ou contrapoder), equilíbrio de poderes (ou mesmo equilíbrio orçamentário), forças políticas, etc., o que agora precisa ser rompido, no sentido de ampliar o leque de variáveis que constituem o próprio poder, o sistema político e o jurídico. Neste sentido ver o texto de MORIN. Introduction à la pensée complèxe, p. 26. Adverte o autor, no particular, que enquanto a ciência clássica via o simples por detrás do complexo, a ciência moderna, ao contrário, vê o complexo por detrás do simples. Ela tenta, desse modo, evitar a redução do real a seus elementos mais simples e conservar o caráter global, mesmo que ele inclua contradições da realidade estudada. A ciência moderna se recusa, então, a separar, a dividir, mesmo que seja para "melhor" compreender uma realidade sempre múltipla e complexa: a inter ou transdisciplinaridade não é um capricho, mas o reconhecimento que os recortes não são nada além de projeções do observador, que não têm outra validade que a de permitir o conhecimento. Quando um conhecimento mais fino dos fenômenos supõe sua integridade na diversidade, aí torna-se necessário transgredir os recortes e recusar as mutilações que estes trazem consigo. É importante, então, voltar a recortar o campo de estudo, transformar o objeto estudado.
} 
de comportamentos e condutas que geram conseqüências patrimoniais, extra-patrimoniais, criminais, fiscais e morais as mais diversas.

De outro lado, tem-se uma certa fragmentação de formas jurídicas solicitadas por usos tão diversos que se torna impossível manter sua unidade original de formas. Isso ocorre, por exemplo, com a noção de estabelecimento público em direito administrativo, ou com a noção de serviço público; forçadas que estão a encobrir realidades cada vez mais distintas, elas nem mesmo podem receber uma definição que permita dar conta da sua própria natureza, ao menos de forma fechada e exclusiva.

Como reagem os teóricos e os práticos diante deste processo fático? Em geral, quando reconhecem existir certa desordem e deslocamento dos seus parâmetros normativos matriciais (suas fontes de direito), atestam o surgimento de instituições normativas novas ou que merecem ser incorporadas pelo sistema, inclusive para que este não perca sua função clássica de mantença da ordem e da paz social. Ocorre que isto nem sempre é possível, ou não é possível na extensão desejada pelos juristas de plantão guardiões da tradição dos costumes induzidos pela lei (qual seja, a de que se volte à normalidade unívoca dos sensos comuns daquelas fontes referidas). ${ }^{18}$

É assim que tanto juristas quanto economistas vêm entendendo, há muito tempo, as chamadas crises do direito, enquanto que o tão esperado retorno à normalidade tarda em manifestar-se, revelando que a crise das instituições se assevera muito mais estrutural do que conjuntural.

Decorre daqui as possibilidades daquilo que Michel Miaille chama de forte inserção no imaginário dos juristas, ${ }^{19}$ para os fins de, criativamente, enfrentar as demandas acima referidas, criando formas e fórmulas capazes de darem conta, ao menos conjunturalmente, dos problemas decorrentes daquele pluralismo societário e relacional. ${ }^{20}$ Com tal comportamento, eles vão incrementando as fontes do direito e abrindo as possibilidades para que outros fenômenos sociais, não estanques, mas orgânicos, contribuam no processo de delimitação regulativa do cotidiano

\footnotetext{
${ }^{18}$ A tentativa isolada de se aumentar penas restritivas de liberdade para coibir crimes chamados de hediondos no Brasil não tem dado os resultados esperados pelo legislador, eis que o problema da criminalidade não se restringe somente à políticas de coação estatal. Ver o texto de AZEVEDO; GUERRA. Infância e violência doméstica: os novos pequenos mártires.

${ }_{19}$ MIAILLE, Michel. Désordre, droit et science. In: AMSELEK, P. (Dir.). Théorie du droit et science, p. 81. Destaca o autor no texto que os modos de pensar e raciocinar utilizados e comprovados desde o princípio dos tempos modernos devem ser revistos. Nesse sentido, os juristas seriam, ainda hoje, vítimas de uma ilusão de ótica: a de ver o trabalho científico através do prisma positivista que remonta ao século XIX e que fragmentou, para os pesquisadores, as disciplinas ditas "duras" desde, ao menos, o começo deste século.
} 
de modo oxigenado e democrático. Com isto, se experimenta uma outra maneira de se pensar e constituir as relações jurídicas, o que implica um necessário aggiornamento da própria teoria jurídica. ${ }^{21}$

Mas como isto se projeto para o Direito Administrativo propriamente dito. Este é o tópico que passo a abordar.

\section{Possibilidades empírico-criticistas de soluções às insuficiências das fontes tradicionais do Direito Administrativo}

Já tive oportunidade de dizer que os níveis de complexidade que apresenta a sociedade contemporânea estão a exigir a revisão dos paradigmas que informam classicamente o problema da Administração Pública (reduzida a aspectos técnico-burocráticos de competência exclusiva do aparelho estatal ${ }^{22}$ ), isto porque a Administração Pública no Brasil, assim com na maior parte dos países da América Latina, tem se pautado pela profunda indiferença em relação às aspirações e reais demandas da comunidade alcançada por suas práticas oficiosas, gerida por corporações que se apoderam do Estado e o transformam em aparelho ou instrumento de seus interesses privados.

Em tal cenário caótico, em que boa parte da cidadania apresentase deveras inerte e passiva diante da privatização dos espaços públicos, ao mesmo tempo em que opta por tentar dar respostas às suas demandas à margem das fontes tradicionais de regulação e ordenação do Estado (lei e regulamentos, por exemplo), muitas vezes de forma inclusive ilícita, o

\footnotetext{
${ }^{20}$ Em nível de Direito Administrativo no Brasil, temos o processo de cooptação normativa feito pelo Estado quando do reconhecimento institucional, inclusive por lei, das ações de voluntariado praticadas por diversos agentes sociais no âmbito do cuidado com a coisa pública e mesmo em serviços públicos, como escolares, cuidados com praças e locais públicos; da mesma forma o ocorrido com as organizações não governamentais e o terceiro setor, bem como com a legislação que regulamentou as parcerias públicoprivadas.

${ }^{21}$ Como quer BONGIOVANNI. Costituzionalismo e Teoria del Diritto, p. 51 et seq., isto é, agrega-se de valor social o processo mesmo de constituição do jurídico, a partir da necessária participação de todos os atores que são atingidos por ele. Numa mesma perspectiva, ver o texto de ARNAUD. Repenser un droit pour l'époque post-moderne, 1999.

22 Veja-se que a teoria mais tradicional do Direito Administrativo tem insistido na idéia de que ele serve, fundamentalmente, às atividades estatais (executivas, legislativas e judiciais) e de governo. De uma maneira mais sofisticada, trabalhando com conceitos múltiplos, por exemplo, Augustín Gordillo, em seu Tratado de derecho administrativo, 1998, insiste na concepção de que o Direito Administrativo (ou a função administrativa) diz respeito, fundamentalmente, às ações estatais tradicionais. No Brasil, Diogo de Figueiredo Moreira Neto, em sua obra Curso de direito administrativo, p. 04, é taxativo em afirmar que: é comum, por isso, num primeiro vislumbre sobre o Direito Administrativo, conotá-lo principalmente às regras de funcionamento do Estado, enquanto que o Direito Constitucional seria, precipuamente, a disciplina das regras de sua estruturação. Estabeleço melhor esta crítica em meu livro LEAL, Rogério Gesta. Estado, sociedade e Administração Pública, 2006.
} 
que reclama resposta urgente é qual o modelo de Administração Pública e de Estado Administrador necessário para lidar com tamanhos desafios e contingências societais como os que estou apresentando?

Tenho que uma Administração e um Estado Administrador que se permita deixar perpassar permanentemente pela Sociedade, criando mecanismos e instrumentos de comunicação não coatada pela ideologia e projetos das elites dominantes, mas abertos a todas as possibilidades de expressão e reivindicação civilizada advinda da comunidade, e mais, comprometido com determinados pressupostos procedimentais de conduta gestacional, dentre os quais destaco: (a) observar os vetores axiológicos universais não metafísicos, como os direitos humanos e fundamentais, que estão postos como elementos fundadores, finalidades e objetivos de uma comunidade, em regra pela via de comandos constitucionais; (b) estabelecer procedimentos de interlocução de forma permanentemente aberta e crítica às proposições assertóricas de todos os atores sociais que se encontram sob sua égide, numa perspectiva de entendimento e consenso, consciente da natureza permanentemente tensional de tal tarefa, para fins de constituir, executar e avaliar políticas públicas de gestão compartida dos interesses sociais; (c) explicitar os argumentos de justificação e fundamentação que pretendem legitimar os atos administrativos formais e materiais que conduzirão a gestão pública, para os efeitos de esgarçar as possibilidades de controle social, jurídico e político, curativos e preventivos, dos seus resultados.

A partir daqui, impõe-se o acatamento da diferença e do pluralismo do universo de interessados/alcançados pelas políticas públicas levadas a cabo pelo Estado Administrador e, com isto, garantir a diversidade, buscando a unidade na gestão dos interesses e bens assegurados pelo sistema jurídico vigente, rompendo com a fatispécie autoritária de poder e de modelo de Estado burocrata e decisor, até então hegemônica na formação dos quadrantes administrativos da coisa pública no Brasil.

Em tal perfil de Estado, Sociedade e Administração Pública, por certo que as tradicionais e pouco flexíveis noções de fontes do direito administrativo - lei e regulamento -, não são suficientes para dar conta da função apaziguadora do direito e de seus próceres, impondo-se aos gestores públicos, aqui tomados como uma comunidade aberta de atores, uma compreensão profunda deste fenômeno e de suas conseqüências multifacetadas, superando assim a tese de que a complexidade da admi-

A \& C R. de Dir. Administrativo e Constitucional, Belo Horizonte, ano 7, n. 28, p. 11-26, abr./jun. 2007 
nistração pública dificulta a participação social.

Percepções arcaicas sobre a Administração Pública e seus instrumentos regulatórios trabalham com a idéia de que o tema da administração pública possui um grau de complexidade e especificidade que vão desde sua dimensão gramatical/lingüística, até a sua operacionalização, eis que conta com um universo categorial tão próprio e pontual que só é alcançado pelos já iniciados em sua ciência, deixando os incautos cidadãos comuns do povo sem compreensão sígnica dos seus enunciados e discursos, o que inviabiliza, por conseqüência, a compreensão de suas práticas, eis que decorrência da operacionalização daqueles conceitos e discursos. Em tal cenário, o que resta à sociedade é tão somente avaliar os resultados das ações e políticas públicas, sendo-lhe vedada o atingimento dos níveis de discussão e deliberação sobre a concepção/eleição daquelas ações e políticas - questões restritas às instituições competentes. ${ }^{23}$

De outro lado, na mesma linha de raciocínio, sustentam que a participação social na gestão da coisa pública encontra limites cognitivos e institucionais, os primeiros, demarcados pela impossibilidade da comunidade política ter discernimento pleno dos temas que estão envolvidos no âmbito da administração pública, eis que destituída de conhecimentos adequados para tanto; a segunda, delimitados pela falta de organicidade institucional e política desta comunidade, capaz de lhe outorgar uma compleição física e institucional mínima para se mover e agir representativamente.

Ledo engano, a uma, porque estas teses partem de pressupostos equivocados e ultrapassados, quais sejam, a de que somente os mecanismos e instrumentos da democracia representativa (voto, partidos políticos, parlamento, etc., leis e regulamentos) é que têm a competência e legitimidade exclusiva à representação dos interesses sociais, a duas, o fato de que a sociedade civil contemporânea não consegue se articular/ mobilizar em torno de suas demandas, a ponto de veicular propostas, ações e cobranças eficazes em termos de gestão da coisa pública; a três, que falta aos atores sociais hodiernos condições mínimas de compreensão dos atos da administração pública.

Veja-se que o modelo de democracia representativa clássica da Idade Moderna, fundado na idéia de representação política total, não conse-

${ }^{23}$ Ver, a título exemplificativo, o texto de BOVERO. Una grammatica della democrazia, p. 137 et seq.

A \& C R. de Dir. Administrativo e Constitucional, Belo Horizonte, ano 7, n. 28, p. 11-26, abr./jun. 2007 
guiu se desincumbir com total êxito das suas tarefas sociais e populares, transformando-se muito mais em espaços de composição de interesses privados, apropriando-se do Estado e imprimindo-lhe feições meramente intermediativas dos projetos econômicos hegemônicos — por vezes agindo como gerenciador de tensões sociais limítrofes, promovendo ações públicas paliativas e assistencialistas, meramente contingenciais, sem tocar nas causas fundantes destes conflitos. ${ }^{24}$ Tais fatos levaram este modelo a uma crise de identidade (por que não se sabe a quem representam), de eficácia (por que sequer respondem por suas competências normativas), e de legitimidade (por que não são mais refratários às demandas sociais emergentes, agregadas e reprimidas), o que, inexoravelmente, atingiu os resultados de suas ações normativas (leis e regulamentos administrativos).

Quero sustentar, com isto, que trata-se de verdadeira ficção ideológica a assertiva de que o universo temático da administração só pode ser abarcado a partir de sua linguagem ordinária - e por suas expressões tradicionais, como leis e regulamentos -, em nome da precisão técnica e da correção científica, eis que estes argumentos remontam à justificativas demasiadamente positivistas, cuja intenção é tão somente excluir do processo de cognição, compreensão, interlocução, deliberação e execução das ações consectárias, os não iniciados, criando um feudo lingüístico a partir do qual se exercitam as arbitrariedades de poder.

Não estou querendo pregar aqui que a lei e o regulamento não cumprem mais uma função normativa importante, somente que ao lado deles encontram-se hoje movimentos sociais e demandas públicas que estão a desafiar os seus sentidos e significados, tarefa esta que somente uma hermenêutica e uma interpretação comprometida com aqueles pressupostos axiológicos anteriormente referidos podem dar conta (entenda-se hermeneutas e intérpretes).

Aqueles pressupostos, enquanto fundacionais de uma Administração Pública Democrática e Comunicativa, tomam como ponto de partida um conceito procedimental de poder político e social, em que há uma relação umbilical e necessária entre processo de democratização da sociedade e processo de transformação desta mesma sociedade, lócus privilegiado da produção de relações e das possibilidades conceituais e operacionais

\footnotetext{
${ }^{24}$ Estamos falando dos programas de subsídios paternalistas dos governos em geral, no âmbito da produção rural, vale refeição, auxílio creche, auxílio desemprego, assentamentos de sem terra, etc. Tratei disto no texto LEAL. Gestão pública compartida e organizações sociais. In: LEAL, Rogério Gesta; ARAUJO, Luiz Ernani Bonesso de. Direitos sociais e políticas públicas, p. 35-72.
} 
do poder. Tal ponto de partida implica reconhecer que o processo de democratização do poder e da sociedade é permanente e longo, mediado, de um lado, por uma linguagem e comunicação política includente e aberta, e de outro lado, pela interação de instituições políticas tradicionais, pelos valores da esfera societária na qual se encontram estas instituições, e pelos movimentos sociais organizados ou espontâneos, questões estas que estão permanentemente a tensionar as possibilidades de sentido das fontes tradicionais que regulam a matéria (lei e regulamentos).

Em outras palavras, estou falando que as fontes tradicionais do direito administrativo encontram-se no seio de um novo contrato da civilidade, que não é mais contrato civil nem contrato civil com o Estado, mas um contrato de cada um com todos que fazem parte da comunidade nacional (quiçá internacional, em alguns aspectos). Este contrato justificaria as novas formas de legitimidade que ressaltam o caráter ainda nacional do Estado, no qual a violência exercida deve ser limitada, controlada e justificada; ${ }^{25}$ criaria as novas formas de solidariedade nas quais o Estado seria também o catalisador de inúmeros circuitos de reciprocidade e solidariedade que necessitam definição. Aqui, trata-se de reaproximação entre o social e o político, ou da repolitização dos laços sociais, ligando-os aos direitos sociais e à cidadania, dando às próprias fontes tradicionais do direito nova roupagem e legitimidade.

O problema que se coloca a esta mediação e interação são os seus princípios e fundamentos matriciais, dando as condições de exercício do poder - mais particularmente o exercício do poder administrativo em prol dos interesses comunitários-solidários. Estes princípios e fundamentos estão alojados, em nosso sentir, no catálogo axiológico estabelecido pelo sistema jurídico vigente, desde e prioritariamente a dicção constitucional hodierna no país, até os ordenamentos infraconstitucionais.

Estamos dizendo que os parâmetros valorativos a serem perseguidos pela República e Federação brasileira estão postos de forma induvidosa, e revelam-se suficientes para o cumprimento das promessas da modernidade: emancipação, autonomia, liberdade e igualdade do homem fundadas na sua capacidade de ser no mundo, vinculando inclusive e principalmente as fontes declinativas do direito administrativo (leis e

\footnotetext{
${ }^{25}$ Estou falando do excesso de Medidas Provisórias, por exemplo, na realidade brasileira, representação objetiva da disposição coativa de vontade do Presidente da República em tornar matéria de seu interesse em lei, sem a prévia apreciação congressual.
} 
regulamentos). A isto se encontra atrelada a Administração Pública, porém, este senso comum não tem se revelado suficiente para promovê-las e concretizá-las, porque faltam adesões institucionais e sociais para tal desiderato. Para conseguí-la de forma democrática, nada mais aconselhável do que o procedimento de compartilhar coletivamente ações a ela voltadas, a começar por ações cognitivas e compreensivas sobre o universo posto ao enfrentamento: interesses comunitários, prioridades públicas, políticas públicas, gestão administrativa, visando a constituição de pactos semânticos e pragmáticos definidores destas realidades voltados ao consenso e entendimento, mesmo que circunstanciais. ${ }^{26}$

A par disto, para operacionalizar tal perspectiva, é necessário construir uma linguagem comum capaz de ser codificada e compreendida pelo homem comum do povo, principal fonte e destinatário de toda e qualquer ação administrativa estatal, ultrapassando pois os signos herméticos e nebulosos dos códigos lingüísticos jurídicos tradicionais (leis e regulamentos), que se projetaram e mesmo demarcam a Administração Pública contemporânea, principalmente em sua vertente técnicoburocrática, o que impossibilita a aproximação política dos seus termos e práticas por parte da cidadania em geral, enclausurando-os nas mãos dos já iniciados e institucionalizados agentes sociais, bem como negando a natureza mediadora e interativa que deveria ter esta linguagem.

E é a própria Administração Pública que deve — em meu sentir e destacadamente - criar condições à instituição de uma comunicação e linguagem (mesmo normativa e regulamentaria) decodificada e democrática, com o que permitirá a validação racional das questões normativas e operativas de suas ações - já não mais suas, mas de toda a comunidade - , isto porque, tal validez, passa a ser compreendida como dependente de um processo intersubjetivo, regulado por razões e por posições tomadas racionalmente. Esta medida permitirá — ao menos metodologicamente - que Administrador e Administrado facilitem o processo de entendimento, visando o consenso, a partir do uso de uma linguagem que busca, agora, elucidar a própria linguagem administrativa em seus mecanismos de uso na comunicação cotidiana entre os participantes de uma comunidade; é a linguagem se apresentando como mediadora das relações intersubjetivas. ${ }^{27}$

\footnotetext{
${ }^{26}$ Haja vista que estes conceitos e ações, tradicionalmente, vêm sido dados como verdades absolutas pela dicção do Estado Administrador.
} 
Qualquer Administração Pública para se configurar como democrática e comunicativa precisa, então, contar/construir o maior número possível de adesão social legítima, adquirida através de ações comunicativas permanentes (tensionais e conflituosas em face de tratar de interesses eventualmente distintos), com todos os agentes envolvidos e alcançados pelo exercício do poder político - institucionais ou não. Ao mesmo tempo, pelo fato das ações administrativas cotidianas comportarem pretensões, sejam de verdade proposicional, de correção normativa ou veracidade subjetiva, devem elas satisfazer um requisito essencial: serem suscetíveis de fundamentação e crítica constantes, retroalimentadoras do controle e depuração social (aqui o esgarçamento necessário das fontes tradicionais do Direito Administrativo).

Por outro lado, não temos dúvidas (com Habermas ${ }^{28}$ ) do caráter precário e contingencial do entendimento e do acordo conseqüente buscado/ atingido por esta Administração Pública Comunicativa, aqui concebida como um processo, através de procedimentos, pois os êxitos consensuais para ações públicas pontuais nem sempre conduzem a cenários absolutamente estáveis, pelo contrário,

a estabilidade e a univocidade são mais a exceção na prática comunicativa cotidiana. Mais realista é a imagem que nos oferece a etnometodologia de uma comunicação difusa, frágil, constantemente submetida a revisão e só lograda por alguns instantes, em que os implicados se baseiam em pressuposições problemáticas e não declaradas, sempre movendo-se por tentativas desde logo naquilo que estão de acordo, para o seguinte..$^{29}$

Isto se explica pelo simples fato do reconhecimento da complexidade que marca as relações sociais contemporâneas, sempre em permanente mutação e ampliação de suas demandas e conflitos, porém, o que se busca na Administração Púbica e com ela, é a garantia de um espaço público

\footnotetext{
${ }^{27}$ A linguagem, aqui, assume a função de mediadora entre os falantes, objetivando o entendimento, compreendido como um processo de obtenção de um acordo entre sujeitos lingüísticos e interativamente competentes. Neste sentido, ver HABERMAS. La soberanía popular como procedimiento: un concepto normativo de lo publico. In: ___. Jürgen Habermas: moralidad, ética y política. Para o autor, há em qualquer linguagem voltada à comunicação não coatada, visando o entendimento autônomo e livre, pelo menos, quatro pretensões de validade que precisam ser justificadas simultaneamente: (a) pretensão de verdade, que exige o cumprimento das condições de existência do conteúdo proposicional, para que este possa ser verdadeiro; (b) a pretensão de retitude ou adequação, que exige do ato de fala que ele seja correto em relação a um contexto normativo vigente; (c) a pretensão de sinceridade, que objetiva tornar conhecidas as experiências e as vivências do falante, e, por fim, (d) a pretensão de que ato comunicativo seja inteligível, para que possa haver comunicação. Tais pretensões podem e devem ser projetadas em qualquer forma regulamentadora da atividade administrativa, assim como em sua execução e avaliação, sempre pública e aberta.

${ }^{28}$ Ver apud HABERMAS. Strukturwandel der Öffentlichkeit, p. 49 et seq.
} 
de enfrentamento de todas as particularidades deste cenário, acolhendo a diversidade e a diferença como elementos imprescindíveis para o debate, a deliberação e a execução das políticas públicas norteadoras das ações públicas voltadas à comunidade como um corpo político orgânico e ativo. É este plano de visibilidade plena e plana que deve marcar o novo modelo de gestão pública compartida, o lugar que nela ocupam leis e regulamentos, criando as condições objetivas e subjetivas para que a participação política da cidadania seja condição de possibilidade da Administração Pública Democrática de Direito.

Resumen: El presente trabajo intende desarollar el tema del la ley y del reglamento como fuentes formales y tradicionales del Derecho Administrativo, así como sus debilidades adelante de las nuevas relaciones sociales.

Abstract: This paper intend work the issues involving the law and the regulation like what formal and traditional Administrative Law sources, analyzing its weakness in front of the news social relations.

Palabras claves: Fuentes del Derecho. Ley y Reglamento. Hermenêutica.

Key-words: Law's Sources. Law and Regulations. Hermeneutics.

\section{Referências}

ALFONSO, Luciano Parejo. Derecho administrativo. Madrid: Ariel, 2002.

ARAGÃO, Lucia Maria de Carvalho. Razão comunicativa e Teoria social crítica em Jürgen Habermas. Rio de Janeiro: Tempo Brasileiro, 1992.

ARNAUD, André Jean. Repenser un droit pour l'époque post-moderne. Paris: PUF, 1999.

AZEVEDO, Maria Amélia; GUERRA, Viviane Nogueira de Azevedo. Infância e violência doméstica: os novos pequenos mártires. São Paulo: IPUSP/Lacri, 2000.

BETANCOR, August. Las administraciones independientes: um reto para el Estado social y democratico del derecho. Madrid: Siglo Veinteuno, 2002.

BONGIOVANNI, Giorgio. Costituzionalismo e Teoria del Diritto. Roma: Laterza, 2006.

BONNARD, Roger. Précis de Droit Administratif. Paris: LGDJ, 2001.

BOVERO, Michelangelo. Una grammatica della democrazia. Millano: Trotta, 2002.

CAETANO, Marcelo. Direito administrativo. Coimbra: Coimbra Ed., 2003.

CHEVALLIER, Jean Jacques. Lordre pratique. In: Le droit en procés. Paris: PUF, 2000.

CRETELLA JR., José. Curso de direito administrativo. Rio de Janeiro: Forense, 2000.

GASPARINI, Diógenes. Direito administrativo. São Paulo: Saraiva, 2004.

GORDILLO, Agustín. Tratado de derecho administrativo. Buenos Aires: Depalma, 2002. t. 1.

${ }^{29}$ ARAGÃO. Razão comunicativa e Teoria Social Crítica em Jürgen Habermas, p. 29. 
GRECO, Guido. Argomenti di diritto amministrativo. Milano: Giuffrè, 2002.

HABERMAS, Jürgen. La soberanía popular como procedimiento: un concepto normativo de lo publico. In: .Jürgen Habermas: moralidad, ética y política. Madrid: Alianza, 1993.

HABERMAS, Jürgen. Strukturwandel der Öffentlichkeit. Boon: Darmstadt, 1978.

LEAL, Rogério Gesta. Estado, sociedade e Administração Pública. Porto Alegre: Livr. do Advogado, 2006.

LEAL, Rogério Gesta. Gestão pública compartida e organizações sociais. In: LEAL, Rogério Gesta; ARAUJO, Luiz Ernani Bonesso de. Direitos sociais e políticas públicas. Santa Cruz do Sul: Edunisc, 2001. t. 1.

LEAL, Rogério Gesta. Hermenêutica e direito: considerações sobre a teoria do direito e os operadores jurídicos. Santa Cruz do Sul: Edunisc, 2002.

MATA MACHADO, Edgar. Elementos de teoria geral do direito. Belo Horizonte: Ed. UFMG, 1995.

MIAILLE, Michel. Désordre, droit et science. In: AMSELEK, P. (Dir.). Théorie du droit et science. Paris: PUF, 2001.

MIRANDA, Pontes de. Fontes e evolução do direito civil brasileiro. São Paulo: Forense, 1981.

MOREIRA NETO, Diogo de Figueiredo. Curso de direito administrativo. Rio de Janeiro: Forense, 1996.

MORIN, Edgar. Introduction à la pensée complèxe. Paris: ESF, 1990.

NORONHA, Fernando. Direito e sistemas sociais: a jurisprudência e a criação do direito para além da lei. Florianópolis: UFSC, 1998.

RICO, Martins Alvarez. Princípios generales de organización de las Administraciones Públicas. Madrid: Civitas, 2004.

RIVERO, Jean. Direito administrativo. Coimbra: Almedina, 1981.

TÁCITO, Caio. Direito administrativo. Revista de Direito Administrativo, Fundação Getúlio Vargas, Rio de Janeiro, n. 140, 1980.

Informação bibliográfica deste texto, conforme a NBR 6023:2002 da Associação Brasileira de Normas Técnicas (ABNT):

LEAL, Rogério Gesta. Limites de esgotamento da lei e do regulamento como fontes do Direito Administrativo no Brasil: aspectos introdutórios. A\&C Revista de Direito Administrativo e Constitucional, Belo Horizonte, ano 7, n. 28, p. 11-26, abr./jun. 2007. 